Revue bibliographique pour le domaine irano-aryen

\title{
Elspeth R.M. Dusinberre, « Resistance, revolt and Revolution in Achaemenid Persia: Response »
}

\section{Rémy Boucharlat}

\section{(2) OpenEdition}

1 Journals

\section{Édition électronique}

URL : http://journals.openedition.org/abstractairanica/46749

DOI : 10.4000/abstractairanica.46749

ISBN : 1961-960X

ISSN : 1961-960X

Éditeur :

CNRS (UMR 7528 Mondes iraniens et indiens), Éditions de l'IFRI

Référence électronique

Rémy Boucharlat, «Elspeth R.M. Dusinberre, « Resistance, revolt and Revolution in Achaemenid

Persia: Response » », Abstracta Iranica [En ligne], Volume 37-38-39 | 2018, document 86, mis en ligne le 30 décembre 2018, consulté le 27 septembre 2020. URL : http://journals.openedition.org/ abstractairanica/46749; DOI : https://doi.org/10.4000/abstractairanica.46749

Ce document a été généré automatiquement le 27 septembre 2020.

Tous droits réservés 


\title{
Elspeth R.M. Dusinberre, « Resistance, revolt and Revolution in Achaemenid Persia: Response »
}

\author{
Rémy Boucharlat
}

\section{RÉFÉRENCE}

Elspeth R.M. Dusinberre, « Resistance, revolt and Revolution in Achaemenid Persia: Response » in John J. Collins and J.G. Manning (eds.). Revolt and Resistance in the Ancient Classical World and the Near East. In the crucible of Empire. Leiden-Boston: Brill, 2016, p. 122-137 (Culture and History of the Ancient Near East, 85)

1 Dans le cadre des questionnements que pose cet ouvrage, l'A se demande s'il est possible et légitime envisager d'évaluer la résistance au pouvoir central perse à partir des données archéologiques. La présence des apports impériaux, importations et imitations, affectent en général seulement l'élite ; elle est repérable (voir les bâtiments de type achéménide dans le Caucase; certains types de vases), mais quelle est sa signification en l'absence de données textuelles? Quel est l'impact sur la population ordinaire? Les textes concernent le plus souvent les élites, et même les données archéologiques, le plus souvent, du fait des choix des archéologues eux-mêmes (voir également dans ce volume le cr Pierre Briant. «À propos de l'« empreinte achéménide » (Achaemenid impact) en Anatolie).

2 Par les pratiques funéraires et le mobilier qu'emploie l'élite manifeste plus son statut social que son identité ethnique. Cette identité n'est par ailleurs pas toujours perceptible par les aménagements et le mobilier funéraire entre élite locale et Perses, ces derniers pouvant adopter des pratiques de la région où ils vivent. Les différentes provinces (Lycie, Carie, Phrygie, etc.) illustrent une très grande diversité de tombes, que détaille l'A, visible dès l'aspect extérieur des tombes : tumuli, stèles, sarcophages, tombes rupestres, piliers, architecture construite. Les traditions locales sont 
manifestement plus fortes que l'imitation de l'art achéménide, ce qui laisse supposer que ces tombes sont en général celles de l'élite locale. Les documents archéologiques permettent-ils vraiment d'évaluer une résistance relativement faible sur le long terme, par rapport aux textes qui expriment plus directement, quant à eux, les attitudes et les actions de résistance ou rébellion?

\section{AUTEURS}

\section{RÉMY BOUCHARLAT}

UMR 5133 CNRS-Université de Lyon 